\title{
FORMULATION OF CHLORPHENIRAMINE MALEATE TABLETS USING CO- PROCESSED EXCIPIENT AS A FILLER AND BINDER
}

\author{
Yandi Syukri $^{1 *}$ ), Romdhonah ${ }^{1}$, Anisa Nur Fazzri ${ }^{1}$, Rio Fandi Sholehuddin ${ }^{1}$, Aris Perdana \\ Kusuma $^{1}$
}

${ }^{1}$ Department of Pharmacy, Islamic University of Indonesia

Received January 30, 2019; Accepted May 17, 2019

\begin{abstract}
Co-Processed Excipient (CPE) is technological innovation for tablet preparation through the direct compression method with a quick and straight forward manufacturing process because it improves the compressibility and flowability. This research aimed to formulate and evaluate of chlorpheniramine maleate tablets using spray dried CPE as filler and binder. The spray dried CPE containing MCC PH 101, and Kollidon ${ }^{\circledR}$ K30 was made into tablets through a direct compression method. Meanwhile, Ludipress ${ }^{\circledR}$ and Avicel ${ }^{\circledR}$ PH 102 were used as filler-binder comparators. All the prepared tablet formulations were then evaluated for weight variation, hardness, friability, disintegration time, content uniformity of active ingredient, and dissolution test. The physical properties of tablets with CPE as a filler and binder produced an average weight of $151.65 \pm 1.53$ $\mathrm{mg}, 5.92 \pm 0.38 \mathrm{~kg}$ of hardness, $0.06 \pm 0.051 \%$ friability, $520.00 \pm 2.00$ seconds of disintegration time, and $99.24 \pm 0.15 \%$ content uniformity of active ingredient. The comparators indicated better disintegration time than CPE ( $\mathrm{p}<0.05)$, while the dissolution test showed that more than $80 \%(\mathrm{Q})$ of the amount of active ingredient was dissolved in 30 minutes. CPE could be successfully used to prepare tablet dosage form, and the tablets had fulfilled the standards of pharmacopoeia.
\end{abstract}

Keywords: Avicel® PH 102; chlorpheniramine maleate; co-processed excipient; Kollidon® K30

\section{INTRODUCTION}

As the most widely used dosage form, oral administration, including tablets, in particular, accounts for $70-80 \%$ of any pharmaceutical preparations mainly because of its manufacturing simplicity, dose accuracy, and high level of patient compliance (Syukri et al., 2015). Meanwhile, despite the well-known significance of excipients for the success of pharmaceutical products, there has been only a minor development of new excipients. They are rarely introduced to the market probably because discovering novel excipients is challenging or due to the modest profit. Novel excipients can be produced from one of the following routes: new chemical entities developed as further excipients, new grades of existing excipients, or new combinations of existing excipients (Wang et al., 2015).
The poor mechanical properties of active ingredients in a high dose make tabletting difficulty in tablet production, mostly forcing formulators to apply granulation techniques that provide appropriate compression properties of drug-excipient agglomerates. Direct compression (DC), however, is a preferable tablet manufacturing method due to its simplicity, rapidity, and cost-effectiveness (Al-Zoubi, Odeh and Nikolakakis, 2017). A DC process requires appropriate diluents with good flowability and compaction properties, and formerly, single-component excipients were physically mixed to obtain such diluents. Today, the basic DC process has even been successfully simplified by the innovative development of co-processed excipients (Aljaberi et al., 2013). 
The new technology of co-processed excipients can meet the ever-increasing demand for excipients with multiple functions in DC tabletting obtained by including one excipient in the particle structure of another employing hot-melt extrusion, co-drying, coprecipitation, or freeze-thawing. In coprocessing, the interaction between excipients occurs at a sub-particle level to maintain or develop desirable properties, improve functionality, and conceal undesired properties of each component. The characteristics and tabletting properties of co-processed excipients with multiple functions are superior to those of a single substance or physicallymixed excipients concerning compatibility, intrinsic flow, lubricating efficiency, binding properties, and blending properties (Rojas and Kumar, 2011). Meanwhile, as an alternative to preparations of co-processed compressible powder mixture, the spray drying method is reportedly able to improve the compression properties of hypromellose and $\alpha$-lactose monohydrate as a binder (Mužíková et al., 2014), with erythritol, mannitol, various maltodextrins, crospovidone, colloidal silicon dioxide, polyoxyethylene 20 sorbitan monooleate (Gonnissen et al., 2008), HPMC, lactose, and PVPP (Wang et al., 2015).

Prior to this current research, a study of MCC PH 101, lactose, and Kollidon ${ }^{\circledR}$ K30 as co-processed excipients (CPE) in spray drying was conducted to examine their compressibility as a filler and binder. The findings showed that spray-dried MCC $\mathrm{PH}$ 101, lactose, and Kollidon® K30 could serve as an alternative filler and binder in a direct compression process, but the best CPE consisted of MCC PH 101 and Kollidon® K30 only. The study showed that the optimum CPE had lower tapping index and higher hardness than the physical mixture. It indicates that the optimum CPE had good flowability and compatibility characters. Then, the optimum CPE also reported no chemical changes following the characterization through infrared spectrophotometer (IR), scanning electron microscope (SEM), differential scanning calorimetry (DSC), and X-ray diffraction (XRD) (Kusuma et al., 2017).
This research involved chlorpheniramine maleate as the drug model, the first generation of alkylamine antihistamines commonly used to treat symptoms of allergies, such as rhinitis and urticaria(Lashkarbolooki et al., 2013). The appropriate method for the preparation of lowdose chlorpheniramine maleate is the direct compression. While pharmacists and pharmaceutical companies are seeking new approaches to improve drug products, they also focus more on exploring and enhancing excipients with better physicochemical properties (Eraga et al., 2015). Therefore, excipient compressibility, flowability, and carrying capacity in tabletting should be taken into consideration (Dave et al., 2017).

This study aimed to formulate tablets of chlorpheniramine maleate through direct compression with $\mathrm{CPE}$ as the filler-binder. The tablets would then be evaluated for the fulfilment of requirements from the Indonesian Pharmacopeia to control the quality of pharmaceutical preparations.

\section{METHODS}

\section{Materials}

Chlorpheniramine maleate was manufactured by Brataco Ltd. Company Indonesia, Kollidon® ${ }^{\circledR}$ K30 was the product of Hangzhou Nanhang, and microcrystalline cellulose (MCC PH 101) and Avicel® PH 102 came from Asahi Kasei Chemicals. Ludipress ${ }^{\circledR}$ was obtained from BASF Indonesia, and primogel, magnesium stearate, as well as aerosil were produced by Brataco Ltd. Company Indonesia. All the materials were of pharmacopeial grades, and other solvents were of analytical grades.

\section{CPE Preparation}

A 100-g mixture of MCC PH 101 $(79.63 \%)$ and Kollidon® K30 (20.37\%) was suspended in $1000 \mathrm{ml}$ of water to obtain a suspension of $10 \% \mathrm{w} / \mathrm{v}$ co-processed excipient. A spray dryer (The BUCHI Mini Spray Dryer B-290) with 1-mm nozzle was used to suck the suspension. The constant spray drying parameters consisted of $120^{\circ} \mathrm{C}$ inlet temperature, $4 \mathrm{ml} / \mathrm{min}$ suction speed, and 3 Bars of pump pressure. The obtained powder 
was then dried in an oven at $50^{\circ} \mathrm{C}$ for 24 hours. Physical properties evaluation and characterization of CPE optimum proportions have been reported previously (Jacob et al., 2007; Kusuma et al., 2017).

\section{Tablet Preparation}

Tablets were prepared from $4 \mathrm{mg}$ of chlorpheniramine maleate with the various proportions of each filler and binder (CPE, Avicel ${ }^{\circledR} \quad \mathrm{PH} \quad 102$ and Ludipress $\left.{ }^{\circledR}\right)$, disintegrant (Primogel), lubricant (magnesium stearate) and glidant (Aerosil) to attain $150 \mathrm{mg}$ of the total quantity. All of the materials were homogeneously mixed, then followed by compression into a tablet with direct compression method by using the singlepunch tablet compression machine (Korsh EK $0)$. The machine was set to produce diameters, thickness, hardness and weight in the same conditions. Table I shows the composition of three different tablet formulations.

Table I. Formulations of chlorpheniramine maleate tablets with CPE (quantity for a single tablet)

\begin{tabular}{|c|c|c|c|}
\hline \multirow[t]{2}{*}{ Ingredient } & \multicolumn{3}{|c|}{ Amount (mg) } \\
\hline & F1 & $\mathbf{F 2}$ & F3 \\
\hline Chlorpheniramine maleate & 4 & 4 & 4 \\
\hline $\mathrm{CPE}$ & 129.5 & - & - \\
\hline Avicel $^{\circledR}$ PH 102 & - & 129.5 & - \\
\hline Ludipress $^{\circledR}$ & - & - & 129.5 \\
\hline Primogel & 12 & 12 & 12 \\
\hline Magnesium stearate & 3 & 3 & 3 \\
\hline Aerosil & 1.5 & 1.5 & 1.5 \\
\hline Total quantity & 150 & 150 & 150 \\
\hline
\end{tabular}

\section{Tablet Evaluation}

The parameters of tablet evaluation included hardness, friability, weight variation, and disintegration time. Weight average was tested according to the Indonesian Pharmacopeia from the measurement of the weight of each tablet (20 tablets in total) (Anonim, 1995), followed by determining the weight variation with the formula: the standard deviation is divided by the average weight and multiplied by 100 . Ten tablets were tested for their hardness using a hardness tester (Erweka TBH 125). To determine the percentage of friability, ten tablets were weighed and then rotated at $25 \mathrm{rpm}$ for 4 minutes in a friability tester followed by the calculation of the total remaining weight. A disintegration tester (Erweka ZT 502) was used to individually determine the disintegration time of six tablets per formulation with aquadest at $37 \pm 0.5 \mathrm{oC}$ followed by the calculation of the mean disintegration time. The United States
Pharmacopeia was referred for the content uniformity assessment. Ten tablets were tested to determine whether the concentration of active ingredient in each tablet ranged between $93 \%$ and $107 \%$ of the label claim; if so, the USP requirement would be claimed fulfilled by the batch (Anonim, 2014; United States Pharmacopeial Convention, 2014).

\section{In-vitro Tablet Dissolution}

The paddle stirrer of dissolution equipment (Erweka DT 708) was set in a dissolution medium $(900 \mathrm{ml}$ of $\mathrm{pH} 7.4$ phosphate buffer) rotating at $75 \mathrm{rpm}$ and a maintained temperature of $37 \pm 0.5^{\circ} \mathrm{C}$. Then, using a fitted pre-filter syringe, $5 \mathrm{ml}$ dissolution medium sample was taken at specific time intervals, and the drug release was analyzed based on the absorbance measured at $262 \mathrm{~nm}$. The current quantity of dissolution medium was used to replace the volume taken at each interval of time, and then the calculation and time plotting of the 
percentage of released chlorpheniramine maleate were performed (Anonim, 2014; United States Pharmacopeial Convention, 2014).

\section{RESULTS AND DISCUSSION Tablet Evaluation}

Table II shows the evaluation results for chlorpheniramine maleate tablets with different fillers-binders. The parameters include hardness, weight variation, disintegration time, active-ingredient content uniformity, and friability in formulations containing CPE (F1), Avicel® PH 102 (F2), and Ludipress ${ }^{\circledR}(\mathrm{F} 3)$.

Table II. Results of chlorpheniramine-maleate tablet evaluation with various fillers and binders

\begin{tabular}{lrrr}
\multicolumn{1}{c}{ Evaluation } & F1 & F2 & \multicolumn{1}{c}{ F3 } \\
\hline Weight variation $(\mathrm{mg})$ & $151.65 \pm 1.53$ & $151.55 \pm 0.6$ & $150.05 \pm 0.6$ \\
\hline Weight variation, CV (\%) & 0.4 & 1.01 & 0.4 \\
\hline Diameter (mm) & $7.04 \pm 0,00$ & $7.09 \pm 0.00$ & $7.07 \pm 0.00$ \\
\hline Thickness (mm) & $3.48 \pm 0.02$ & $3.77 \pm 0.01$ & $2.93 \pm 0.04$ \\
\hline Hardness (kg) & $5.92 \pm 0.38$ & $6.57 \pm 0.35$ & $4.73 \pm 1.11$ \\
\hline Friability (\%) & $0.06 \pm 0.051$ & $0.09 \pm 0,033$ & $0.09 \pm 0.07$ \\
\hline Disintegration time (sec) & $520.00 \pm 2.00$ & $15.67 \pm 2.08$ & $131.33 \pm 6.43$ \\
\hline Content uniformity (\%) & $99.24 \pm 0.15$ & $97.88 \pm 0.10$ & $98.87 \pm 0.17$ \\
\hline
\end{tabular}

Weight variation is evaluated to guarantee the right amount of active ingredient in each of the tablets. The weights variations of each formulation with optimum $\mathrm{CPE}(\mathrm{F} 1)$, Avicel ${ }^{\circledR}$ PH 102 (F2), and Ludipress ${ }^{\circledR}(\mathrm{F} 3)$ were $0.4 \%$; $1.01 \%$; and $0.4 \%$, respectively, indicating a small variation. All of the formulations had $<1 \%$ friability with the longest disintegration time in the formulation containing CPE. As the time remained below 900 seconds, the formulations were considered meeting the criteria determined in the Indonesian Pharmacopeia (Anonim, 1995).

Weight variation is affected by flow properties and equipment conditions during the study. In addition, SEM analysis showed that Kollidon ${ }^{\circledR} \mathrm{K} 30$ was invisible as it had enveloped Avicel@ PH 102 (Kusuma et al., 2017), thereby enhancing the flow properties of the excipients. In evaluating the uniformity of tablet size, the parameters evaluated were tablet diameter and thickness. The results of the uniformity evaluation of the size were F1 with a diameter of $7.04 \mathrm{~mm}$ and $3.48 \mathrm{~mm}$ thick; F2 with a diameter of $7.07 \mathrm{~mm}$ and a thickness of $3.77 \mathrm{~mm}$ and F3 with a diameter of $7.09 \mathrm{~mm}$ and thickness of $2.93 \mathrm{~mm}$. Factors that can influence uniformity in size are flow velocity, mixture homogeneity, and punch press stability. This uniformity of size is related to the die diameter used and the amount of powder entering the die. A good size criterion is: if a tablet has a diameter of not less than $11 / 3$ and is not more than 3 times the thickness of the tablet (Anonim, 1979).

In addition, tablets should be strong enough to withstand mechanical shocks while they are manufactured, packaged, shipped, and dispensed, which can be fulfilled when the hardness falls between 4 and $8 \mathrm{~kg}$ with $<1 \%$ friability (United States Pharmacopeial Convention, 2014). Table II indicates that the hardness and friability of all of the formulated tablets have met the mechanical property criteria. The investigation could be clarified that MCC showed low elastic recovery and good compressibility. This condition will reduce tablet failures, include sticking, capping, lamination and binding (Osamura et al., 2016).

According to the Pharmacopeia, 1\% maximum mass loss or $0.8 \%-1.0 \%$ weight loss should be fulfilled by tablets tested for 
crushing strength without laminating, capping, or breaking during the test. Tablet crushing strength can greatly influence the rate of drug release. The increased crushing strength of a tablet generally means the decreased rate of drug release because of reduced porosity of the tablet (Eraga et al., 2015). Differences in the profiles of drug release are likely caused by the changes in crushing strength experienced by the tablet batches studied (Komersová et al., 2016).

Evaluation should also be done for the disintegration time, which is the time required by a tablet to completely break down and penetrate the basket mesh in a disintegration test. Such tests represent the process of a tablet breaking down into particles in the gastrointestinal tract, which, according to the Indonesian Pharmacopeia, should last no longer than 15 minutes for an uncoated tablet (Anonim, 2014), and the tablet disintegration time in this research has fulfilled the requirement.

Tablets containing optimum CPE as the filler-binder are influenced by their hardness and friability as well as the nature of Kollidon ${ }^{\circledR}$ K30 as the CPE component. Such component will turn into gel when it interacts with water, thus trapping other components and preventing them from dissolving, which consequently results in longer disintegration time. Meanwhile, tablets with Avicel ${ }^{\circledR} \mathrm{PH}$ 102 as the filler-binder have shorter disintegration time because such component has multiple functions as a filler, binder, and disintegrant.

Content uniformity test is conducted to ensure the fulfilment of the standard for active ingredient concentration in a tablet, which will influence the results of a therapy. For chlorpheniramine maleate tablets, the concentration of active ingredient should range from $93 \%$ to $107 \%$ (Anonim, 2014). Both powder homogeneity and weight uniformity affect the concentration of active ingredient in tablets. This study found that the concentrations of chlorpheniramine maleate in Formulation 1, 2, and 3 reached $97.88 \%, 99 \%$, and $98.87 \%$, respectively.

\section{In-vitro Tablet Dissolution}

To determine the concentration of active ingredient dissolved in a medium, a dissolution test is performed in vitro. Tablet dissolution is strongly influenced by the disintegration time, which will also affect the bioavailability. Figure 1 shows the dissolution profile of chlorpheniramine-maleate tablets with CPE (F1), Avicel® PH 102 (F2), and Ludipress ${ }^{\circledR}(\mathrm{F} 3)$ as the fillers-binders.

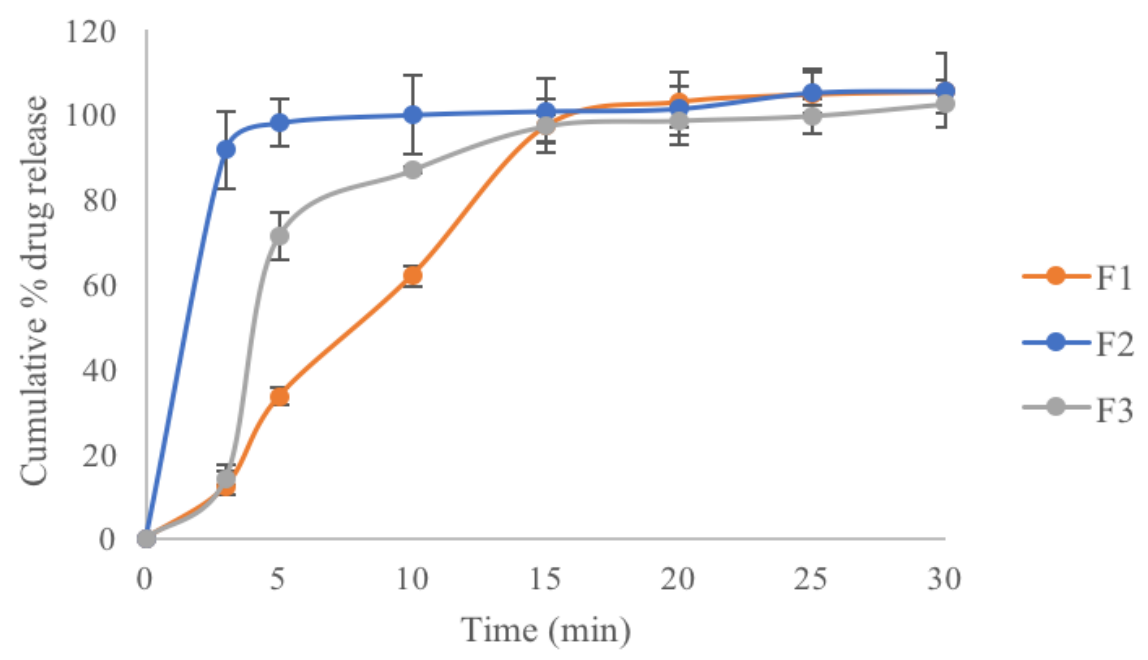

Figure 1. Dissolution characteristics of chlorpheniramine maleate tablets containing different fillers and binders $(n=6)$

The formulation with CPE as the fillerbinder has $80 \%$ dissolved active ingredient with longer disintegration time compared to the other formulations. The use of Kollidon ${ }^{\circledR}$
K30 as a component of CPE in tablets affects the disintegration time since such component naturally forms a gel mass that obstructs the release of the active ingredient. However, all 
of the formulations in this research had met the dissolution criteria defined by the Indonesia Pharmacopoeia (Anonim, 2014).

This finding is also supported by previous research, which showed that HPMC coprocessed filler prepared by fluid bed coating and spray drying has the potential to be developed as a filler and binder in direct compression method (Dong et al., 2018). Coprocessed excipients also facilitate direct compression of orally disintegrating tablets. Multifunctional excipients exhibited more dominant impact on the investigated tablet properties, especially for tablet disintegration properties (Drašković et al., 2018).

\section{CONCLUSION}

The CPE comprising MCC PH 101 and Kollidon ${ }^{\circledR} \mathrm{K} 30$ as a filler and binder in tablet formulation can improve the compressibility of chlorpheniramine maleate tablets prepared using the direct compression method. The physical properties of a tablet with CPE as the filler-binder were 0.4 weight variation, $5.92 \pm 0.38 \mathrm{~kg}$ hardness, $0.06 \pm 0.051 \%$ friability, $520.00 \pm 2.00$ seconds of disintegration time, and $99.24 \pm 0.15 \%$ content uniformity of active ingredient. Therefore, the tablets had fulfilled the standards of pharmacopoeia.

\section{ACKNOWLEDGEMENT}

The authors would like to thank the Directorate of Research and Pharmaceutical Technology Laboratory of Islamic University of Indonesia for the research facilities and funding.

\section{REFERENCES}

Aljaberi, A., Ardakani, A., Khdair, A., AbdelRahim, S.A., Meqdadi, E., Ayyash, M., Alobaidi, G.M., and Al-Zoubi, N., 2013. Tableting functionality evaluation of Prosolv Easytab in comparison to physical mixtures of its individual components. J Drug Sci. Tech., 23, 499-504.

Al-Zoubi, N., Odeh, F., and Nikolakakis, I., 2017. Co-spray drying of metformin hydrochloride with polymers to improve compaction behavior. Powder Technol., 307, 163-174.

Anonim, 2014. Farmakope Indonesia, V. ed. Departemen Kesehatan RI, Jakarta.

Anonim, 1995. Farmakope Indonesia, IV. ed. Ministry of Health Republic of Indonesia, Jakarta.

Anonim, 1979. Farmakope Indonesia, III. ed. Departemen Kesehatan RI, Jakarta.

Dave, V., Yadav, R.B., Ahuja, R., and Yadav, S., 2017. Formulation design and optimization of novel fast dissolving tablet of chlorpheniramine maleate by using lyophilization techniques. Bull. Fac. Pharm. Cairo Univ. 55, 31-39.

Dong, Q., Zhou, M., Lin, X., Shen, L., and Feng, Y., 2018. Differences in fundamental and functional properties of HPMC co-processed fillers prepared by fluid-bed coating and spray drying. Eur. J. Pharm. Sci., 119, 147-158.

Drašković, M., Djuriš, J., Ibrić, S., and Parojčić, J., 2018. Functionality and performance evaluation of directly compressible co-processed excipients based on dynamic compaction analysis and percolation theory. Powder Technol., 326, 292-301.

Eraga, S.O., Arhewoh, M.I., Uhumwangho, M.U., and Iwuagwu, M.A., 2015. Characterisation of a novel, multifunctional, co-processed excipient and its effect on release profile of paracetamol from tablets prepared by direct compression. Asian Pac. J. Trop. Biomed., 5, 768-772.

Gonnissen, Y., Gonçalves, S.I.V, De Geest, B.G., Remon, J.P., and Vervaet, C., 2008. Process design applied to optimise a directly compressible powder produced via a continuous manufacturing process. Eur. J. Pharm. Biopharm., 68, 760-770.

Jacob, S., Shirwaikar, A.A., Joseph, A., and Srinivasan, K.K., 2007. Novel coprocessed excipients of mannitol and microcrystalline cellulose for preparing fast dissolving tablets of glipizide. Indian J. Pharm. Sci., 69, 633.

Komersová, A., Lochař, V., Myslíková, K., 
Mužíková, J., and Bartoš, M., 2016. Formulation and dissolution kinetics study of hydrophilic matrix tablets with tramadol hydrochloride and different co-processed dry binders. Eur. J. Pharm. Sci., 95, 36-45.

Kusuma, A.P., Syukri, Y., Sholehuddin, R.F., Fazzri, A.N., Romdhonah, and Hakim, R.B.F., 2017. Optimization of Microcrystalline Cellulose PH 101, Lactose, and Kollidon ${ }^{\circledR}$ K 30 To Obtain Co-Processed Excipient Through Spray Drying. Int. J. Drug Deliv. Technol., 7, 83-88.

Lashkarbolooki, M., Hezave, A.Z., Rahnama, Y., Rajaei, H., and Esmaeilzadeh, F., 2013. Solubility of chlorpheniramine maleate in supercritical carbon dioxide. J. Supercrit. Fluids, 84, 29-35.

Mužíková, J., Hávová, S., Ondrejček, P., Komersová, A., and Lochař, V., 2014. A study of tablets with a co-processed dry binder containing hypromellose and $\alpha$-lactose monohydrate. J. Drug Deliv. Sci. Technol., 24, 100-104.

Osamura, T., Takeuchi, Y., Onodera, R., Kitamura, M., Takahashi, Y., Tahara, K., and Takeuchi, H., 2016. Characterization of tableting properties measured with a multi-functional compaction instrument for several pharmaceutical excipients and actual tablet formulations. Int. J. Pharm., 510, 195-202.

Rojas, J., and Kumar, V., 2011. Comparative evaluation of silicified microcrystalline cellulose II as a direct compression vehicle. Int. J. Pharm., 416, 120-128.

Syukri, Y., Fernenda, L., Utami, F.R., Qiftayati, I., Kusuma, A.P., and Istikaharah, R., 2015. Preperation and Characterization of B-Cyclodextrin Inclusion Complexes Oral Tablets Containing Poorly Water Soluble Glimipiride using Freeze Drying Method. Indones. J. Pharm., 26, 71.

United States Pharmacopeial Convention, 2014. U.S. Pharmacopeia National Formulary, USP 37 NF 32. United States Pharmacopeial, Rockville, USA. Wang, S., Li, J., Lin, X., Feng, Y., Kou, X., Babu, S., and Panicucci, R., 2015. Novel coprocessed excipients composed of lactose, HPMC, and PVPP for tableting and its application. Int. J. Pharm., 486, 370-379. 